\title{
The use of polymerase chain reaction to confirm diagnosis in skin biopsies consistent with American tegumentary leishmaniasis at histopathology: a study of 90 cases
}

\author{
Uso da reação em cadeia da polimerase em biópsias de pele para confirmar o diag- \\ nóstico histopatológico consistente com leishmaniose tegumentar americana: um \\ estudo de 90 casos
}

\author{
Rosilene Viana de Andrade ${ }^{1}$ \\ Meline Nogueira Barbosa de Lucena ${ }^{3}$ \\ Sinésio Talhari ${ }^{4}$ \\ Luiz Carlos de Lima Ferreira ${ }^{6}$
}

\author{
Cesare Massone ${ }^{2}$ \\ Anette Chusciak Talhari ${ }^{4}$ \\ Jorge Augusto de Oliveira Guerra
}

\begin{abstract}
BACKGROUND: Cutaneous leishmaniasis is a chronic, infectious disease caused by protozoa of the genus leishmania. The incidence of this disease is high in Brazil, with 19,746 new cases having been detected in 2008. The presence of amastigotes in the cytoplasm of histiocytes constitutes diagnosis of the disease; however, their presence is rarely found in late lesions, making histological diagnosis difficult. Polymerase chain reaction has been shown to represent a highly sensitive and specific technique for the diagnosis of cutaneous leishmaniasis.

OвJECTIVEs: To use polymerase chain reaction to evaluate paraffin-embedded skin biopsies with histopathological features consistent with cutaneous leishmaniasis.

MATERIAL AND METHODS: Polymerase chain reaction amplification of a 120-base-pair fragment of Leishmania kinetoplast DNA (kDNA) minicircles was performed on 90 skin biopsies. The male/female ratio was 75/15. Mean age was 32.36 years, with a median of 31 years, range 4-72 years. Samples were histologically compatible with cutaneous leishmaniasis but a definitive diagnosis could not be made since amastigotes were not found. All cases were histologically classified according to the patterns described by de Magalhães. RESULTS: According to the de Magalhães classification, the most common histological pattern was type IV (exudative granulomatous reaction), which was found in $65.6 \%$ of cases (56/90), followed by type I (exudative cellular reaction) in $21.1 \%$ of cases (19/90) and type III (exudative and necrotic granulomatous reaction) in 12.2\% of cases (11/90). Leishmania DNA was found in $96.7 \%$ of the biopsies $(87 / 90)$.

CONCLUSIONS: Polymerase chain reaction performed by amplifying kDNA is able to confirm a diagnosis of cutaneous leishmaniasis with a high degree of sensitivity in cases in which histopathology is consistent with a diagnosis of cutaneous leishmaniasis but not definitive. Keywords: Leishmaniasis, cutaneous; Polymerase chain reaction; Skin
\end{abstract}

Resumo: FunDAMENTOS: Cutaneous leishmaniasis is a chronic, infectious disease caused by protozoa of the genus leishmania. The incidence of this disease is high in Brazil, with 19,746 new cases having been detected in 2008. The presence of amastigotes in the cytoplasm of histiocytes constitutes diagnosis of the disease; however, their presence is rarely found in late lesions, making histological diagnosis difficult. Polymerase chain reaction has been shown to represent a highly sensitive and specific technique for the diagnosis of cutaneous leishmaniasis.

OBJECTIVES: To use polymerase chain reaction to evaluate paraffin-embedded skin biopsies with histopathological features consistent with cutaneous leishmaniasis.

MATERIAL AND METHODS: Polymerase chain reaction amplification of a 120-base-pair fragment of Leishmania kinetoplast DNA (kDNA) minicircles was performed on 90 skin biopsies. The male/female ratio was 75/15. Mean age was 32.36 years, with a median of 31 years, range 4-72 years. Samples were histologically compatible with cutaneous leishmaniasis but a definitive diagnosis could not be made since amastigotes were not found. All cases were histologically classified according to the patterns described by de Magalhães.

RESULTS: According to the de Magalbães classification, the most common histological pattern was type IV (exudative granulomatous reaction), which was found in $65.6 \%$ of cases (56/90), followed by type I (exudative cellular reaction) in $21.1 \%$ of cases (19/90) and type III (exudative and necrotic granulomatous reaction) in 12.2\% of cases (11/90). Leishmania DNA was found in 96.7\% of the biopsies (87/90). CONCLUSIONS: Polymerase chain reaction performed by amplifying kDNA is able to confirm a diagnosis of cutaneous leishmaniasis with a high degree of sensitivity in cases in which histopathology is consistent with a diagnosis of cutaneous leishmaniasis but not definitive.

Palavras-chave: Leishmaniose cutânea; Pele; Reação em cadeia da polimerase

Received on 22.10.2010.

Approved by the Editorial Board and accepted for publication on 22.11.2010.

* Study conducted at the Heitor Vieira Dourado Foundation of Tropical Medicine, Manaus, Amazonas, Brazil.

Conflict of interest: None / Conflito de interesse: Nenbum

Financial funding / Suporte financeiro: Superintendência da Zona Franca de Manaus

Master's degree. Pathologist, Heitor Vieira Dourado Foundation of Tropical Medicine, Manaus, Amazonas, Brazil.

PhD. Investigator, Graz University, Graz, Switzerland.

Physician. Investigator, Stem Cell Research Team. Zurich University, Zurich, Switzerland.

PhD. Dermatologist. Heitor Vieira Dourado Foundation of Tropical Medicine, Manaus, Amazonas, Brazil.

Master's degree. Investigator, specialist in infectious diseases, Heitor Vieira Dourado Foundation of Tropical Medicine, Manaus, Amazonas, Brazil.

PhD. Investigator. Pathologist, Heitor Vieira Dourado Foundation of Tropical Medicine, Manaus, Amazonas, Brazil. 


\section{INTRODUCTION}

American tegumentary leishmaniasis (ATL) is an infectious, vector-borne disease caused by intracellular protozoan parasites of the genus Leishmania. ATL may affect the skin, the oral cavity, pharynx and larynx. ${ }^{1}$ ATL is most commonly found in the New World and is endemic in Brazil, where 19,746 new cases of ATL were detected in 2008, 1,737 of which were reported in the state of Amazonas. ${ }^{2}$ In this region, Leishmania (Viannia) braziliensis, Leishmania (V.) guyanensis, Leishmania (V.) naiffi, Leishmania (V.) shawi, Leishmania (V.) lansoni and Leishmania (Leishmania) amazonensis are the most commonly identified species. ${ }^{1}$ The protozoa are transmitted to humans by infected female sandflies of the genus Lutzomyia. ${ }^{1}$ Depending on cellular immune response, clinical forms of ATL include localized cutaneous leishmaniasis (LCL), mucosal leishmaniasis and diffuse cutaneous leishmaniasis. ${ }^{1}$ Diagnosis is established on the basis of epidemiologic information, clinical presentation and laboratory testing. ${ }^{3}$ While the presence of protozoa in the cytoplasm of histiocytes is easily recognizable in skin biopsies of early ATL lesions, they are rarely found in late and chronic lesions. The sensitivity of direct microscopy is not high and isolation in culture may be a lengthy and laborious process. Moreover, in the case of chronic lesions, a definitive and specific diagnosis based only on morphological parameters is difficult, as the granulomatous process may mimic various inflammatory diseases and the parasite load is low. ${ }^{4-7}$ In recent years, polymerase chain reaction (PCR) has been shown to be a highly sensitive and specific technique for the diagnosis of cutaneous leishmaniasis (CL); however, reports concerning the use of PCR for the detection of Leishmania in paraffin-embedded tissue from skin specimens remain sparse. ${ }^{4,8-10}$ In the present study, in order to evaluate the role of PCR in the diagnosis of ATL, PCR sensitivity for the detection of Leishmania was investigated in 90 skin biopsies that were histologically consistent but not specifically diagnostic for ATL.

\section{MATERIALS AND METHODS}

One hundred and eleven biopsies were collected from the database of the Pathology Department at the Amazonas Foundation of Tropical Medicine in Manaus in the state of Amazonas, Brazil. A retrospective search was made for all histology reports from 2003 and 2004 that were consistent with the diagnosis of ATL in which a definitive diagnosis was not possible because amastigotes were not found. Inclusion criteria consisted of: $a$ ) the quality of the slides; and b) the presence of enough material in the paraffin block to perform PCR investigation.

\section{Histopathology}

Skin biopsy specimens were fixed in $10 \%$ formalin and then embedded in paraffin blocks. Two of the authors (RVdD and LCdLF) independently revised all the histopathology sections from each biopsy, looking for the presence of parasites by evaluating 6 fields at 400x magnification stained with hematoxylin and eosin. Periodic acid-Schiff (PAS) and Grocott methenamine silver (GMS) staining were performed in all biopsies. All cases were classified according to the patterns described by de Magalhães ${ }^{11}$ (Figure 1). Moreover, all biopsies were investigated for the presence or absence of the following morphologic criteria: a) ulceration; $b$ ) epidermal hyperplasia; $c$ ) granuloma; $d$ ) necrosis in the dermis.

\section{Polymerase chain reaction (PCR)}

Sections were cut from paraffin-embedded blocks. DNA extraction was performed using phenolchloroform in accordance with the protocol established by Isola et al. with minor modifications. ${ }^{12}$ Triple $10 \mu \mathrm{m}$ sections were cut from paraffin-embedded blocks. After each cut, new disposable blades were used and the blade holder was cleaned using a 100mM solution of sodium hypochlorite to avoid possible cross-contamination with Leishmania DNA. The specimens were deparaffinized by twice immersing them in $1 \mathrm{ml}$ xylene for 10 minutes and then twice immersing them in $1 \mathrm{ml}$ of $100 \%$ ethanol for 10 minutes. After airdrying at room temperature, samples were resuspended in $0.5 \mathrm{ml}$ DNA extraction buffer. DNA was extracted using a phenol/chloroform/isoamyl alcohol preparation. DNA was measured using Leishmania-specific oligonucleotide primers (5GTGGGGGAGGGGCGTTCT-3 and 5- ATTTTACACCAACCCCCAGTT-3) for a 120-base-pair fragment of Leishmania kinetoplast DNA (kDNA) minicircle. Each amplified sample was run on $1.5 \%$ agarose gel electrophoresis, stained with ethidium bromide for 60 minutes and then visualized using ultraviolet light.

\section{Controls}

Fifteen biopsies of ATL (diagnosis confirmed by the histological presence of protozoa) were used as positive controls. Ten cases of different inflammatory skin diseases [leprosy $(n=3)$, cutaneous tuberculosis $(n=3)$, lobomycosis $(n=2)$, chromomycosis $(n=1)$, and atypical mycobacteriosis $(n=1)]$ were used as negative controls. DNA was extracted and amplified using the same method applied to the other test samples.

\section{Institutional Review Board}

This study was approved by the Institutional Review Board of the Amazonas Foundation of Tropical Medicine, Manaus, Brazil, in January 2006 (\#1757/05). 

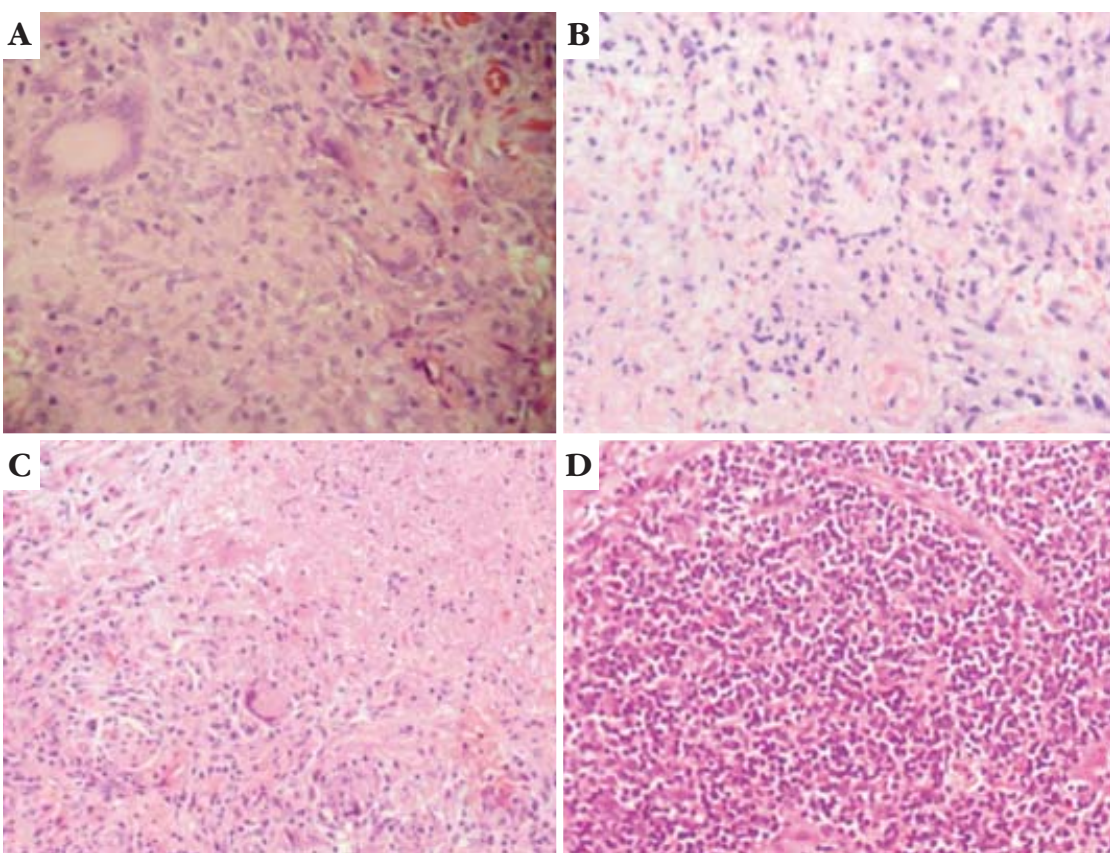

FIGURE 1: Histopathology pattern of ATL - A Exudative tuberculoid pattern - epithelioid granulomatous reaction with lymphocytes, plasma cells and Langhans giant cells. Magnification $400 x$. B. Exudative necrotic pattern - large tissue necrosis, acute vasculitis, histiocytes, plasma cells, lymphocytes and polymorphs. (400x) C. Exudative and necrotic granulomatous pattern - disorganized granulomatous reaction with a central area of necrosis. Magnification 250x. D. Exudative cellular pattern - heavily infiltrated with plasma cells, lymphocytes and scattering of isolated macrophages but no granuloma. Magnification 250x. Hematoxylin and eosin staining

\section{RESULTS}

Ninety biopsies (male/female ratio: 75/15; mean age: 32.36 years; median age: 31 years; range: $4-$ 72 years) were selected. Twenty-one biopsies were excluded, as they did not fulfill the inclusion criteria. When biopsies were re-evaluated histologically, parasites where not found in any slide, and PAS and GMS were negative in all cases. Ulceration was present in $25.6 \%$ of cases (23/90), while epidermal hyperplasia was found in $83.3 \%$ of the cases (75/90). Necrosis and granulomas were found in $25.6 \%$ (23/90) and $78.9 \%$ (71/90) of cases, respectively. The most frequent histopathology pattern was type IV according to the de Magalhães classification (exudative granulomatous reaction), found in $65.6 \%$ of cases (56/90), followed by type I (exudative cellular reaction) found in $21.1 \%$ of cases (19/90), type III (exudative and necrotic granulomatous reaction) found in $12.2 \%$ of cases $(11 / 90)$ and type $\mathrm{V}$ (exudative-tuberculoid reaction) found in 1 single case (1.1\%).

PCR successfully identified Leishmania in $96.7 \%(87 / 90)$ of the cases in the study and in all positive controls $(100 \% ; 15 / 15)$, while all negative controls tested negative $(100 \% ; 10 / 10)$ (Figure 2$)$.

\section{DISCUSSION}

Many different techniques such as isoenzyme electrophoresis, monoclonal antibodies, in situ hybridization, molecular karyotyping and restriction enzyme are currently used to detect Leishmania., ${ }^{1,8,9}$ Compared to PCR, these techniques require a larger quantity of sample material, involve a lengthy technical process and may present difficulties in the interpretation of results. ${ }^{1,8,9}$ Detection of Leishmania by amplification of kinetoplast DNA has been widely described in the literature. ${ }^{8,9,13}$ Previous reports have high-

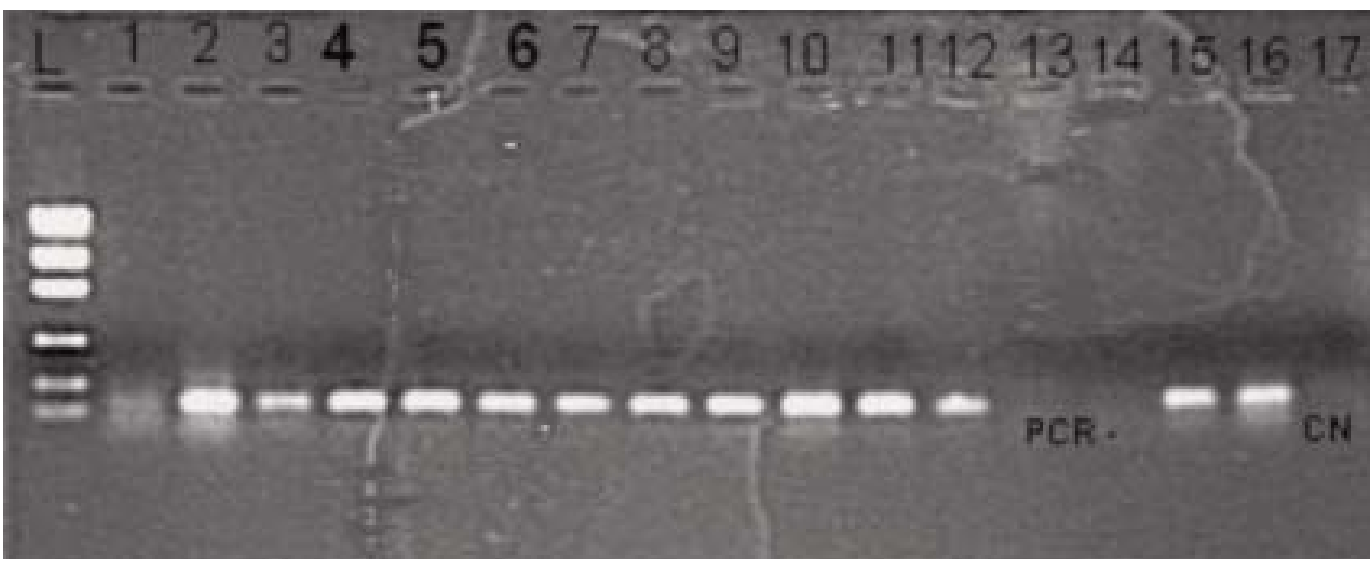

FigURE 2: ATL PCR Results of PCR: lane 15,16: DNA extraction positive from the biopsies of proven positive cases of $\mathrm{CL}$; lanes 1-12 DNA extraction positive from biopsies of cases consistent with $\mathrm{CL}$; lanes 13-14 DNA extraction negative from biopsies of cases consistent with $\mathrm{CL}$; $\mathrm{L}$ $=$ Ladder $; \mathrm{CN}=$ negative control from patients with diseases other than leishmaniasis 
lighted the possibility of amplifying Leishmania DNA from different materials such as samples of scrapings/exudate or frozen samples. ${ }^{8,10}$ Studies on PCR for the identification of Leishmania in paraffinembedded tissue are few and their results have been conflicting. Laskay et al. reported that PCR amplification of $\mathrm{kDNA}$ was able to detect the amastigote of Leishmania aethiopica from skin biopsies with 61\% of sensitivity. ${ }^{5}$ Momeni et al. found $48 \%$ of sensitivity with PCR for $L$. major in 30 out of 63 cases of chronic lupoid leishmaniasis. ${ }^{6}$ This poor sensitivity may be related to DNA inhibitors or to the degradation of DNA during the process of formalin fixing, to DNA extraction, the use of primers specific for $L$. major ribosomal DNA instead of primers specific for kinetoplast, or to the selection of patients with chronic lupoid lesions that probably represent a hypersensitivity reaction of the host rather than a response to the parasite. ${ }^{6}$ Safaei et al. investigated PCR using kDNA primers in two different groups of patients: a group with histologically confirmed leishmaniasis $(n=33)$ and a group of cases histologically consistent with CL but in which amastigotes were not found $(n=26)$. PCR was positive in $100 \%$ and $92 \%$ of cases, respectively. ${ }^{7}$ Similar results have been reported by Lanus et al. Weigle et al. evaluated PCR amplification of kDNA from biopsy lysates in 255 acute and 44 chronic cases of CL, achieving sensitivity of $75.7 \%$ and $45.5 \%$, respectively. ${ }^{14}$ The detection of kDNA in biopsies taken from chronic lesions was enhanced with the use of a chemiluminescence dot blot hybridization assay, which achieved sensitivity of $65.8 \%$ when used alone and $90.9 \%$ when used in combination with DNA extraction of biopsy lysates $(p<0.001) .{ }^{4}$ The results of the present study confirm and expand previous data concerning PCR amplification of kDNA in paraffin embedded tissue. Leishmania DNA was detected in
$96.7 \%$ of cases in the present study, confirming the conclusions of Safei et at., Laskay et al. and Weigle et al. that PCR amplification of kDNA results in higher sensitivity. ${ }^{4-6}$ This sensitivity is comparable to that obtained using frozen samples (84-94\%) or samples of scrapings/exudate $(84-100 \%){ }^{1,8,10}$ Of the cases in the present study, only three tested negative. These negative PCR results may be explained by a low DNA load, biopsy bias, DNA degradation or a different diagnosis. Since direct microscopic examination of samples of scrapings stained with Giemsa also tested negative in all three cases, together with the fact that these three patients failed to return for follow-up visits, it was impossible to confirm or exclude the diagnosis.

As previously reported, a granulomatous reaction was the histopathology pattern most commonly found in this study (78.9\%). The absence of amastigotes in these cases makes histopathological differentiation between leishmaniasis and other granulomatous skin diseases such as cutaneous tuberculosis, sarcoidosis and deep mycotic infections very difficult. ${ }^{47,15-18}$ In most of these cases, only a descriptive report with a diagnosis consistent with ATL is possible because a definitive diagnosis can only be made after an accurate correlation with clinical and follow-up data. On the other hand, PCR amplification of kDNA is able to confirm or exclude a diagnosis of ATL.

\section{CONCLUSION}

Definitive diagnosis of chronic lesions of cutaneous leishmaniasis based only on morphological parameters is difficult, as the granulomatous process may mimic a variety of inflammatory diseases and the parasite load is low. PCR evaluation of paraffin-embedded tissue proved to be a highly sensitive test for the diagnosis of chronic lesions of cutaneous leishmaniasis when other methods failed to detect the parasite. $\square$ 


\section{REFERENCES}

1. Silveira FT, Lainson R, Corbett CE. Clinical and immunopathological spectrum of American cutaneous leishmaniasis with special reference to the disease in Amazonian Brazil: a review. Mem Inst Oswaldo Cruz 2004; 99:239-51.

2. Ministério da saúde. Vigilância epidemiológica. Leishmaniose tegumentar americana. Casos de leishmaniose tegumentar americana. Brasil, Grandes Regiões e Unidades Federadas.1990 a 2008. [acesso 20 Nov. 2010]. Disponível em: http://portal.saude.gov.br/portal/arquivos/pdf/lta.

3. Talhari S, Arias JR, Cunha MGS, Naiff RD, Naiff MF, Freitas RA, et al. Leishmaniose no estado do Amazonas: aspectos clínicos, epidemiológicos e terapêuticos. An Bras Dermatol. 1988;63:433-8.

4. Weigle KA, Labrada LA, Lozano C, Santrich C, Barker DC. PCR-based diagnosis of acute and chronic cutaneous leishmaniasis caused by Leishmania (Viannia). J Clin Microbiol 2002; 40:601-6.

5. Laskay T, Mikó TL, Negesse Y, Solbach W, Röllinghoff M, Frommel D. Detection of cutaneous Leishmania infection in paraffin-embedded skin biopsies using the polymerase chain reaction. Trans R Soc Trop Med Hyg. 1995;89:273-5.

6. Momeni AZ, Yotsumoto S, Mehregan DR, Mehregan AH, Mehregan DA, Aminjavaheri $\mathrm{M}$, et al. Chronic lupoid leishmaniasis. Evaluation by polymerase chain reaction. Arch Dermatol. 1996;132:198-202.

7. Safaei A, Motazedian MH, Vasei M. Polymerase chain reaction for diagnosis of cutaneous leishmaniasis in histologically positive, suspicious and negative skin biopsies. Dermatology. 2002;205:18-24.

8. Reithinger R, Dujardin JC. Molecular diagnosis of leishmaniasis: current status and future applications. J Clin Microbiol. 2007;45:21-5.

9. Mimori T, Sasaki J, Nakata M, Gomez EA, Uezato H, Nonaka S, et al. Rapid identification of Leishmania species from formalin-fixed biopsy samples by polymorphism-specific polymerase chain reaction. Gene. 1998;210:179-86.

10. Faber WR, Oskam L, van Gool T, Kroon NC, Knegt-Junk KJ, Hofwegen H, et al. Value of diagnostic techniques for cutaneous leishmaniasis. J Am Acad Dermatol. 2003;49:70-4.

11. de Magalhães AV, Moraes MA, Raick AN, Llanos-Cuentas A, Costa JM, Cuba CC et al. Histopathology of cutaneous leishmaniasis by Leishmania braziliensis braziliensis. Histopathological patterns and study of the course of the lesions. Rev Inst Med Trop Sao Paulo. 1986;28:253-62.

12. Isola J, DeVries S, Chu L, Ghazvini S, Waldman F. Analysis of changes in DNA sequence copy number by comparative genomic hybridization in archival paraffinembedded tumor samples. Am J Pathol. 1994;145:1301-8.
13. Rodgers MR, Popper SJ, Wirth DF. Amplification of kinetoplast DNA as a tool in the detection and diagnosis of Leishmania. Exp Parasitol. 1990;71:267-75.

14. Lanús EC, Piñero JE, González AC, Valladares B, de Grosso ML, Salomón OD. Detection of Leishmania braziliensis in human paraffin-embedded tissues from Tucumán, Argentina by polymerase chain reaction. Mem Inst Oswaldo Cruz. 2005;100:187-92.

15. de Magalhães AV, Chiarini LH, Raick AN. The histopathology of cutaneous leishmaniasis. Rev Inst Med Trop Sao Paulo. 1982;24:268-76.

16. Ridley DS, Ridley MJ. The evolution of the lesion in cutaneous leishmaniasis. Pathol. 1983;141:83-96

17. Ridley DS, Marsden PD, Cuba CC, Barreto AC. A histological classification of mucocutaneous leishmaniasis in Brazil and its clinical evaluation. Trans R Soc Trop Med Hyg. 1980;74:508-14.

18. Ridley DS, De Magalhaes AV, Marsden PD. Histological analysis and the pathogenesis of mucocutaneous leishmaniasis. J Pathol. 1989;159:293-9.

How to cite this article/Como citar este artigo: Andrade RV, Massone C, Lucena MNB, Talhari AC, Talhari S, Guerra JAO, Ferreira LCL. The use of polymerase chain reaction to confirm diagnosis in skin biopsies consistent with American tegumentary leishmaniasis at histopathology: a study of 90 cases. An Bras Dermatol. 2011;86(5):892-6. 